Article

\title{
Assessment of the Suitability of Wintering Anatidae Habitats before and after Impoundment in the Three Gorges Reservoir Region
}

\author{
Xiuming Li ${ }^{1}$, Ruimei Cheng ${ }^{2,3}$, Wenfa Xiao ${ }^{2,3}$, Ge Sun ${ }^{1}$, Tian Ma ${ }^{1}$, Fuguo Liu ${ }^{4}$, Xiaoyun Liu ${ }^{4}$, Fawen Qian ${ }^{1, *}$ \\ and Kaijun Pan ${ }^{1}$ \\ 1 Key Laboratory of Forest Protection of State Forestry and Grassland Administration, Research Institute of \\ Forest Ecology, Environment and Protection, Chinese Academy of Forestry, Beijing 100091, China; \\ icelxming@gmail.com (X.L.); dasunge@163.com (G.S.); matian_123@126.com (T.M.); \\ punoigwan@163.com (K.P.) \\ 2 Key Laboratory of Forest Ecology and Environment, State Forestry Administration, Research Institute of \\ Forest Ecology, Environment and Protection, Chinese Academy of Forestry, Beijing 100091, China; \\ chengrm@caf.ac.cn (R.C.); xiaowenf@caf.ac.cn (W.X.) \\ 3 Co-Innovation Center for Sustainable Forestry in Southern China, Nanjing Forestry University, \\ Nanjing 210037, China \\ 4 Experimental Centre of Subtropical Forestry, Chinese Academy of Forestry; fuguoliucaf@126.com (F.L.); \\ xiaoyunliucaf@yeah.net (X.L.) \\ * Correspondence: cranenw@caf.ac.cn; Tel.:+86-010-6288-8454
}

check for updates

Citation: Li, X.; Cheng, R.; Xiao, W.; Sun, G.; Ma, T.; Liu F.; Liu, X.; Qian, F.; Pan, K. Assessment the Suitability of Wintering Anatidae Habitats before and after Impoundment in the Three Gorges Reservoir Region. Sustainability 2021, 13, 4743. https:// dx.doi.org/10.3390/su13094743

Academic Editor: Georgios Koubouris

Received: 24 February 2021

Accepted: 19 March 2021

Published: 23 April 2021

Publisher's Note: MDPI stays neutral with regard to jurisdictional claims in published maps and institutional affiliations.

Copyright: (c) 2021 by the authors Licensee MDPI, Basel, Switzerland. This article is an open access article distributed under the terms and conditions of the Creative Commons Attribution (CC BY) license (https:// creativecommons.org/licenses/by/ $4.0 /)$.

\begin{abstract}
In this study, we aimed to understand the distribution of and changes in the habitats suitable for Anatidae wintering in the Three Gorges Reservoir Region (TGRR), China, and to explore the impact of the impoundment during different impoundment periods. Based on species occurrence data for four dominant species of Anatidae and environmental factors, a maximum entropy (MaxEnt) model was used to analyze the suitability of habitats during five impoundment periods. The results show that the main factors affecting Anatidae distribution were temperature and roads before the Three Gorges Project (TGP) and elevation after the TGP. After the TGP, the area of the suitable habitat declined rapidly and then gradually increased with increasing water level. After impoundment, the primary area of increased habitat suitability was the main stream of the Yangtze River from Changshou District to Yunyang County and its tributary in the Kaizhou area. Among the habitats, the central water regions were more suitable than the marginal shoal areas. Anatidae habitats in the TGRR were distributed mainly within the Yangtze River main stream and the surrounding areas before the TGP, and the surrounding areas largely disappeared after the TGP, particularly in Chongqing City and Jiangjin District. In this context, it is challenging to create new protected areas within the habitat suitable for Anatidae in the main stream of the Yangtze River; we propose adding the Anatidae as conservation targets within the existing conservation agencies and implementing a waterbird monitoring program for scientific waterbird conservation and the sustainable development of the reservoir.
\end{abstract}

Keywords: habitat suitability; Anatidae; three gorges reservoir; MaxEnt model

\section{Introduction}

In wetland ecosystems, waterbird communities, mainly the family Anatidae (ducks, geese, and swans), occupy a higher level on the food chain. The Anatidae are of particular importance due to their migratory behavior, wide distribution, and high densities [1], and can act as wetland biological indicators [2]. Changes in Anatidae community dynamics are correlated with water conditions (wetland area, water level, water quality, etc.) [3]. The lower Skjern River in Western Jutland, Denmark, which has been devoid of any waterbirds since drainage and intensive arable tillage began in 1987, is now one of Denmark's 
five most critical freshwater wetlands for waterbirds, suggesting that changes in water conditions in this wetland area have increased the size of the Anatidae community [4]. In addition, dabbling and diving ducks respond differently to high water levels. During floods in the Upper Danube River, $83 \mathrm{~km}$ from the border between Hungary and Slovakia, dabbling ducks dispersed to peripheral waters and diving ducks left the area entirely [5]. As artificial wetlands, reservoirs typically have higher water levels than the surrounding wetlands and can serve as habitats and refuges for waterbirds [6,7]. Regulation of water levels in reservoirs during and after construction can change waterbird habitat communities [8,9]. The suitability of waterbird habitats links the likelihood of species occurrence to environmental variables $[10,11]$, and suitability analyses are often applied in wetland conservation and wetland ecosystem management $[12,13]$.

Species distribution models (SDMs) combine information on species occurrence with relevant climatic $[14,15]$ or environmental predictor variables to infer the nature of the relationships, which are then used to predict species' distributions in space and time. In addition, habitat suitability calculated based on SDMs predicts the main environmental factor determining distribution [16]. With birds commanding considerable attention, SDMs have been widely used in conservation biology [17], invasive species monitoring [18], and predicting bird distributions, as well as more general topics such as modeling avian diversity, niche evolution, and seasonal distribution at the biogeographic scale. Many studies have predicted the distributions of certain endangered Anatidae species and wetland changes and have identified areas for conservation and management [17]. Anatidae breeding habitats are mainly influenced by food sources and habitat structure [19], and factors such as water area, patch density, wetland area, and distance from roads can influence the distribution of wintering habitats [20,21]. SDMs have been used to target species groups [22] or individual species within the Anatidae to identify conservation actions that address gaps for some ignored species [23]. Habitat suitability, river density, and land use/land cover (LUCC) are the main factors impacting the Anatidae in the plains-dominated BeijingTianjin-Wing region of China [24]. The digital elevation model (DEM) was found to be the most important variable in predicting suitable habitats for most Anatidae species in Iran [25].

In the Three Gorges Reservoir Region (TGRR), with its deep gorges and high ravines, the larger water surface after impoundment has provided a larger habitat area for Anatidae. After impoundment, the numbers and populations of some species such as the common goldeneye (Bucephala clangula), common pochard (Aythya ferina), and Eurasian wigeon (Mareca penelope) increased dramatically in this area [26,27]. To investigate the habitat suitable for Anatidae in the TGRR, we collected and compiled data on the distribution of these species and identified the habitat range of Anatidae using a maximum entropy (MaxEnt) model and geographic information system (GIS) technology. In addition, we studied the distribution of suitable habitats and their dynamic changes during different periods to explore the effect of impoundment on Anatidae habitat suitability and provide a reference for scientific waterbird conservation and sustainable reservoir development.

\section{Materials and Methods}

\subsection{Study Area}

The TGRR $\left(28^{\circ} 56^{\prime}-31^{\circ} 44^{\prime} \mathrm{N}, 106^{\circ} 16^{\prime}-111^{\circ} 28^{\prime} \mathrm{E}\right)$ is the region directly or indirectly involved in the submerged water storage of the reservoir of the Three Gorges Dam, including 26 county-level divisions in Chongqing municipality and Hubei province in China (Figure 1). The TGRR is approximately $5.8 \times 10^{4} \mathrm{~km}^{2}$, spanning the low mountain valleys of Yu and the middle-low hills of the parallel ridge and valley of Eastern Sichuan in the transition area from the second to the third terraces of China's terrain with the Daba Mountains to the north and the Yunnan-Guizhou Plateau to the south. The region is located in the central humid subtropical monsoon climate zone with a warm climate and an annual precipitation of $1000-1300 \mathrm{~mm}$. 


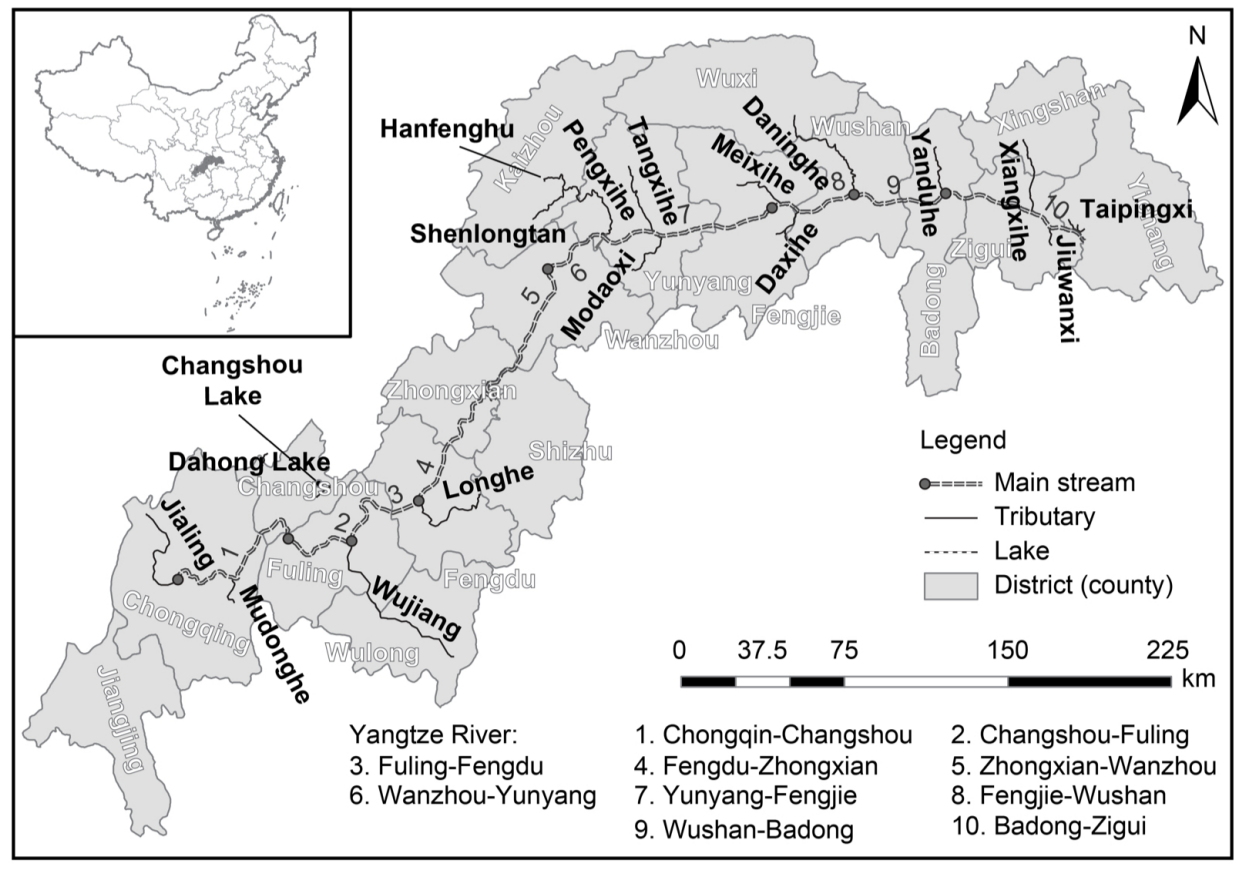

Figure 1. The map shows the location of the Three Gorges Reservoir Region (TGRR) and distribution of the sample routes for waterbird surveys including the mainstream Yangtze River (double dashed line), lakes (dashed line), and tributaries (solid line) in the region. The TGRR is marked by the grey area and all the districts (counties) are labeled.

\subsection{Species Occurrence Data}

From 2000 to 2020, we conducted waterbird surveys by boat in the TGRR during mid-January each year at 10 fixed routes along the Yangtze River and three lakes, as well as along 15 random sample routes on tributaries of the Yangtze River (Figure 1). We conducted the surveys during the day when visibility was high, and the vessel speed was less than $30 \mathrm{~km} / \mathrm{h}$. The survey vessels were typically passenger or fishing boats with fixed routes. At least two investigators were responsible for the surveys on both sides of the route. Because it is difficult to identify species from a distance, photos were taken for later identification. To avoid repeat counting, we ignored flocks flying over from behind. The waterbirds were observed and counted using a monocular scope (Carl Zeiss Terra ED $8 \times 42)$.

The Three Gorges Project (TGP) was officially launched in 1994, and the project commenced with the cutoff of the Yangtze River in 1997. The Three Gorges Reservoir was impounded to $135 \mathrm{~m}$ in 2003, $156 \mathrm{~m}$ in 2006, $172.8 \mathrm{~m}$ in 2008, $171.4 \mathrm{~m}$ in 2009, and $175 \mathrm{~m}$ in 2010. Therefore, all records were divided into five stages: before the TGP, the cut-off period, the cofferdam power generation period, the trial impoundment period, and the stable impoundment period (Table A1). To avoid overfitting the model, we randomly retained one record in each $1 \times 1 \mathrm{~km}$ raster based on the resolution of the environmental data.

The mallard (Anas platyrhynchos), Chinese spot-billed duck (Anas zonorhyncha), falcated duck (Mareca falcata), and Mandarin duck (Aix galericulata) are the dominant species during winter in this region [26]. Based on the results of the waterbird surveys, we compiled 3122 records of the 4 dominant species of Anatidae inhabiting shallow waters, including the species name, the number of individuals, position, survey date, and location. In addition, we used distribution data obtained from two papers written before the TGP, which used a similar survey method [28,29]. All the occurrence points were encoded in an Excel spreadsheet (with columns for species, longitude, and latitude) and saved as a commaseparated values (CSV) files. 


\subsection{MaxEnt Modeling}

The maximum entropy model (MaxEnt Model) (http:/ /biodiversityinformatics.amnh. org/open_source/maxent/ (accessed on 25 December 2020)) is open-source software developed by Phillips et al. to simulate species distributions and ecological niches [30]. The software uses a set of environmental data (e.g., climate data) and species distribution data to find the distribution with the largest possible entropy to predict the suitability for a species given the environmental conditions of each raster. The model also provides receiver operating characteristic (ROC) curves and area under the ROC curve (AUC) values to evaluate the prediction accuracy of the model and the importance of each environmental variable.

Based on the habitat characteristics of the Anatidae [24,31], we selected a digital elevation model (DEM) and five environmental impact factors (temperature, precipitation, population, road density, and land use/land cover (LUCC)) during the five stages. The road density was derived from a density analysis using road data in ArcGIS 10.2 software. The road data for Chongqing were sourced from the National Earth Systems Science Data Center, and the data for Hubei were taken from Landsat images in the Geospatial Data Cloud (http:/ / www.gscloud.cn (accessed on 25 December 2020)), and were interpreted by visual inspection. The other data were downloaded directly from the platforms of the National Earth Systems Science Data Center (http:/ / www.geodata.cn (accessed on 14 December 2020)) and the Resource and Environment Science and Data Center (http: / / www.resdc.cn (accessed on 23 December 2020)) (Table A2).

Following the model requirements, we unified the boundary, resolution $(1 \times 1 \mathrm{~km})$, and coordinate systems of all the environmental impact data, converted them to ASCII format, and performed a spatial autocorrelation analysis and preliminary simulations. The distribution data of the Anatidae and the environmental factor data were imported into MaxEnt 3.4.1 software; $75 \%$ of the occurrence points were randomly selected for model training, and the remaining 25\% were used for testing. In this study, a total of 10 replicates with 5000 iterations were chosen. These parameters produced a convergence threshold of 0.00001 and we used a threshold rule of maximum training sensitivity plus specificity. Background predictions (pseudo-absences points) were included with a maximum of 10,000 background points. Based on the jackknife test results, the relative contribution of each environmental factor was measured by the model to infer the main factors limiting the distribution of the Anatidae. The model was cross-validated and the results were output in the software's logistic format. Although regularization multipliers higher than the default were necessary to achieve optimal model complexity, the values did not significantly improve the model in our study. Therefore, the default regularization values and auto features were used.

\subsection{Analysis and Assessment of the Model}

The constructed MaxEnt model was used to obtain the true skill statistic (TSS) and values for the area under the ROC curve (AUC) as measures of model performance. TSS and AUC values closer to 1 indicate better model performance compared with those further from 1. Generally, the accuracy of the model is considered excellent when the TSS is greater than 0.7 or when the AUC is between 0.9 and 1 ; moderate prediction accuracy is indicated by a TSS of $0.4-0.7$ or when the AUC is between 0.7 and 0.9 .

The simulation results for the five stages were imported into ArcGIS 10.2 software and converted into floating-point raster data. The results of the reclassification showed that the habitat suitability for the family Anatidae was distributed across different water storage periods. Habitat suitability was divided into four levels: high (0.75-1), medium $(0.50-0.75)$, low $(0.25-0.50)$ and unsuitable (0-0.25). The results were processed using the raster calculator tool in ArcGIS to obtain the change in suitability of the habitat for Anatidae from 1995 to 2015. 


\section{Results}

\subsection{Accuracy of the Model and Relative Contributions}

The MaxEnt model achieved mean AUC values of 0.755, 0.961, 0.960, 0.961, and 0.913 for 1995, 2000, 2005, 2010, and 2015, respectively; and TSS values of 0.600, 0.794, 0.749, 0.798 , and 0.746 , respectively. The AUC values were between 0.8 and 1 , and all the TSS values were greater than 0.6 in 2000, 2005, 2010, and 2015, indicating that this model has high accuracy and good applicability. In the percent contribution of temperature in the model, it was highest before the TGP (1995), decreased rapidly after the TGP, increased with the impoundment (2000-2010), and slightly decreased after the stable impoundment period (2015). The percent contribution of the DEM was inferior to the temperature before TGP (1995), increased rapidly and then showed a slightly downward trend after TGP (2000-2015), much higher than the temperature after the stable impoundment period (2015) (Figure 2).

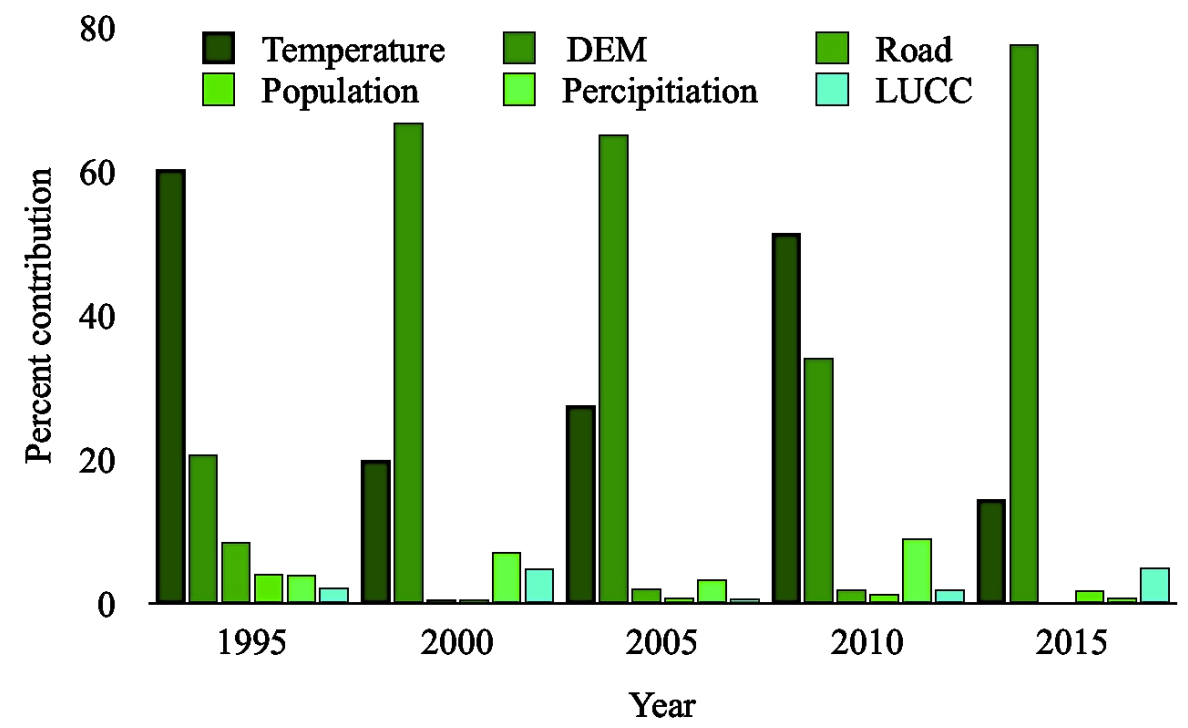

Figure 2. Percent contribution of six factors in the model from 1995 to 2015.

\subsection{Spatiotemporal Distribution of Suitable Habitat}

Before the TGP, we documented more than $15,000 \mathrm{~km}^{2}$ of suitable habitat for Anatidae in the TGRR. The areas of high-, medium- and low-suitability habitats decreased rapidly after the TGP cutoff. With the gradual impoundment from 2005 to 2010 in the TGRR, the areas of high-, medium-, and low-suitability habitats gradually increased (Figure 3).

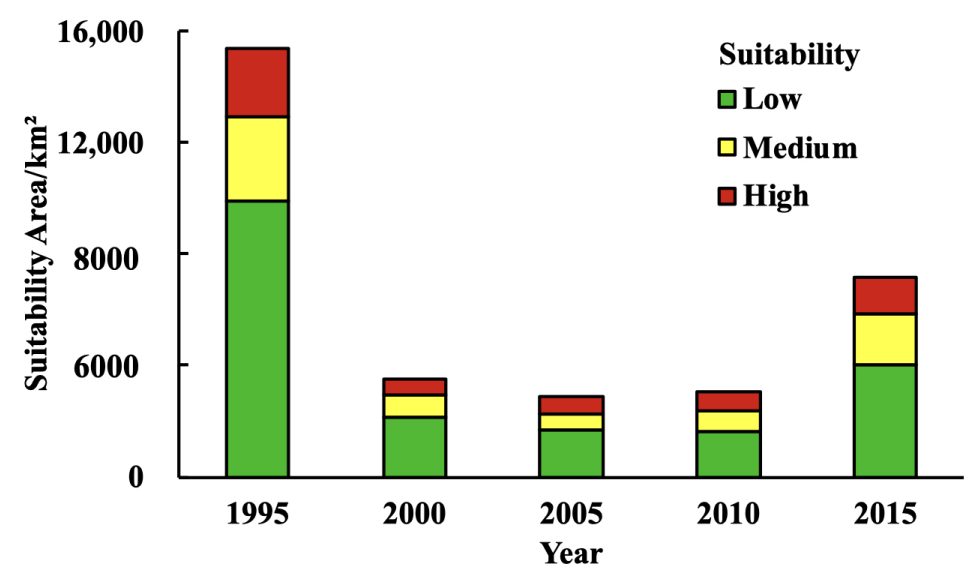

Figure 3. Areas of the three levels of suitable habitats for Anatidae in the TGRR from 1995 to 2015. 
Before the TGP, Anatidae habitat in the TGRR was mainly distributed along the Yangtze River and its surrounding tributaries and lakes. Among these, the highly suitable habitats were continuously distributed along the main steam of the Yangtze River (Figure 4). After the TGP, the surrounding areas disappeared as suitable habitat, particularly in Chongqing City and Jiangjin District. As the suitability of habitats gradually increased, these surrounding areas were partially restored by 2015 .

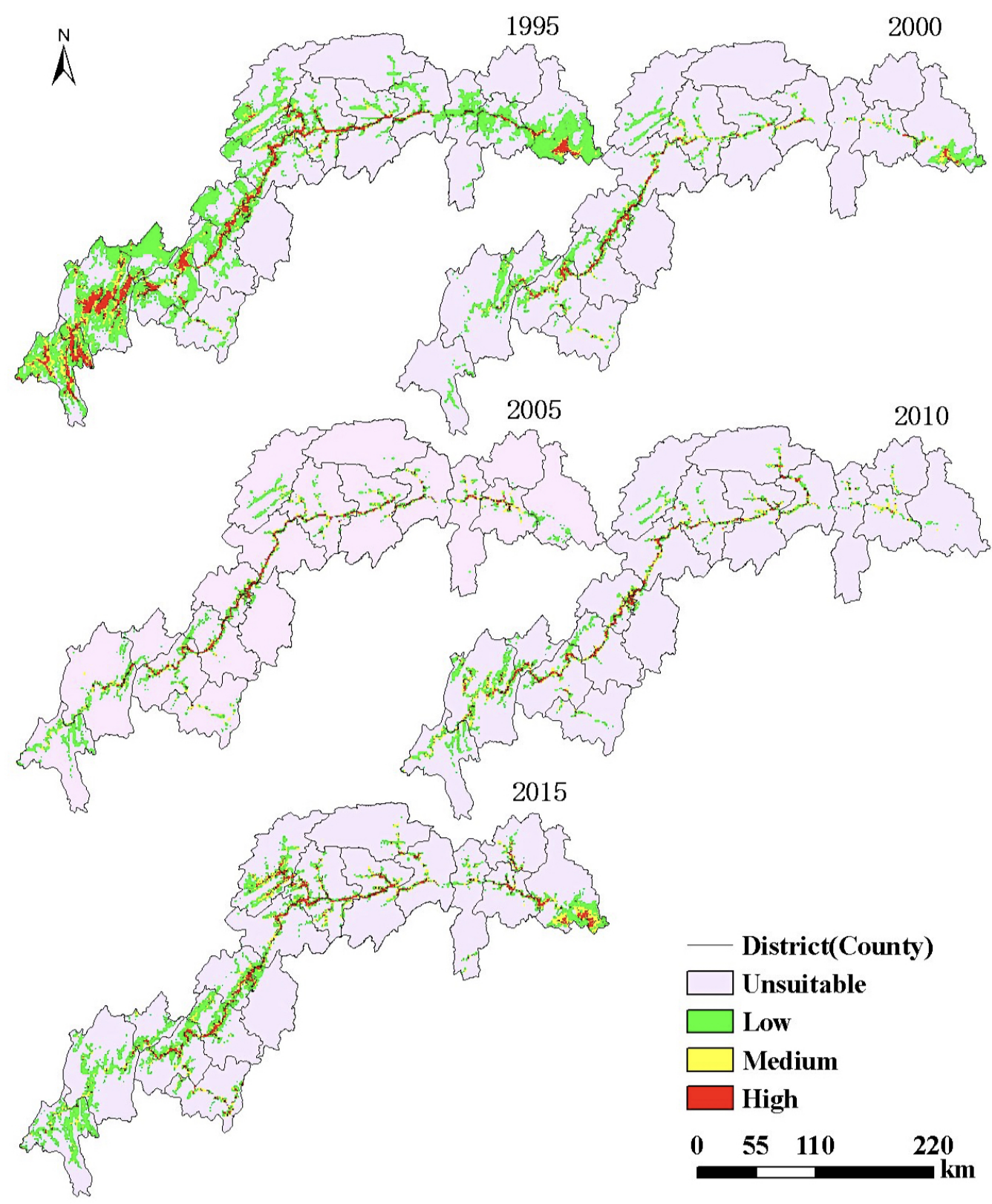

Figure 4. Maximum entropy (MaxEnt) model predicted the distribution of suitable habitats for Anatidae in the TGRR from 1995 to 2015. Red indicates high suitability, yellow indicates medium suitability, and green and lighter purple indicate low and unsuitability, respectively.

\subsection{Changes in Habitat Suitability}

From 1995 to 2015, decreased suitability was observed for almost all habitat in the TGRR; the main decrease occurred between 1995 and 2000 (Figures 5 and 6). The changed area was small and was located mainly on theeastern and western sides of the TGRR from 2000 to 2010. The area of increased suitability was discontinuously distributed along the Yangtze River and its surrounding tributaries from 2010 to 2015. 

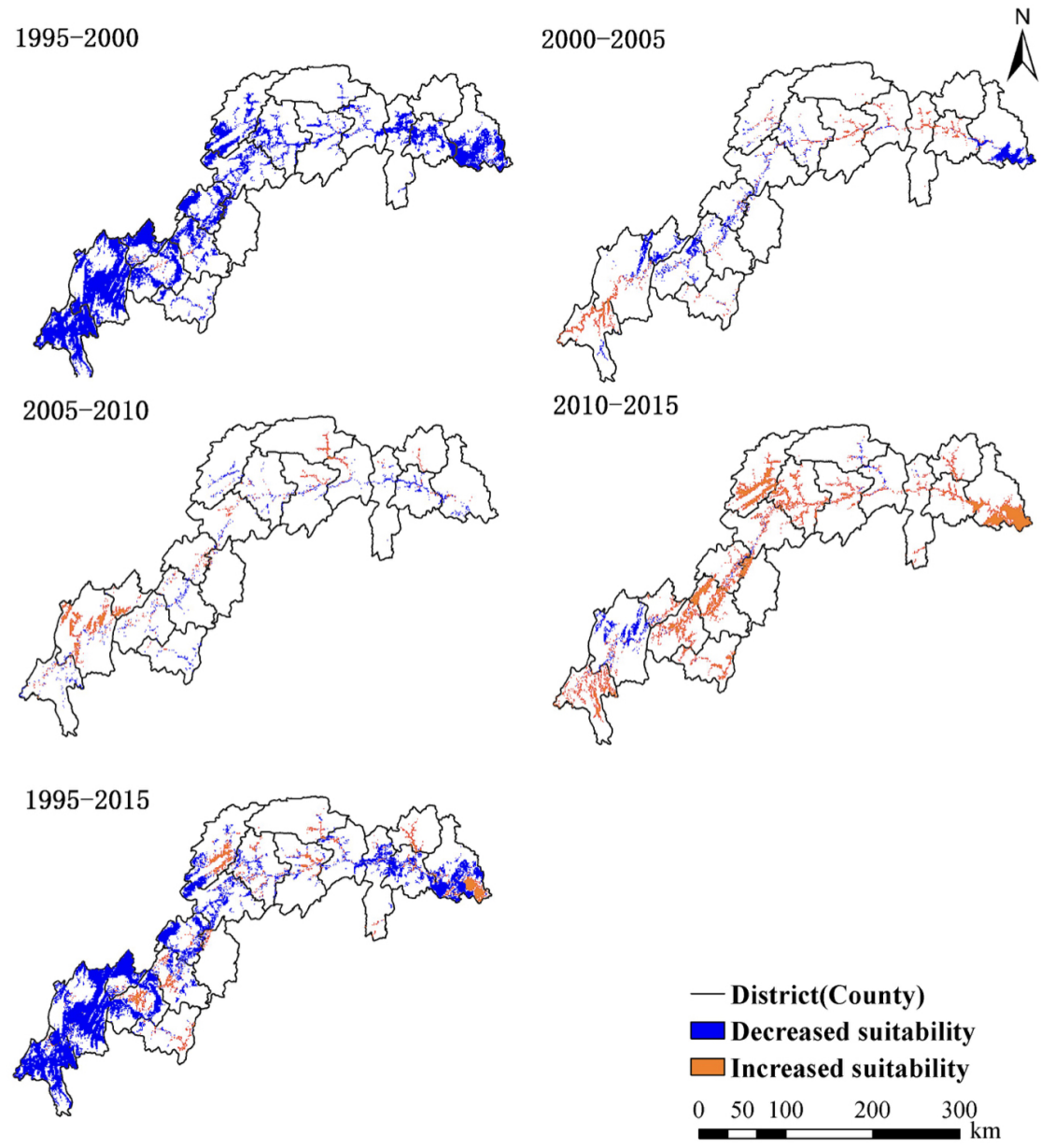

Figure 5. Changes in the distribution and area of habitat suitable for Anatidae in the four intervals between 1995 and 2015 in the TGRR. Blue and orange indicate decreased and increased suitability, respectively. The last figure shows the overall changes from 1995 to 2015.

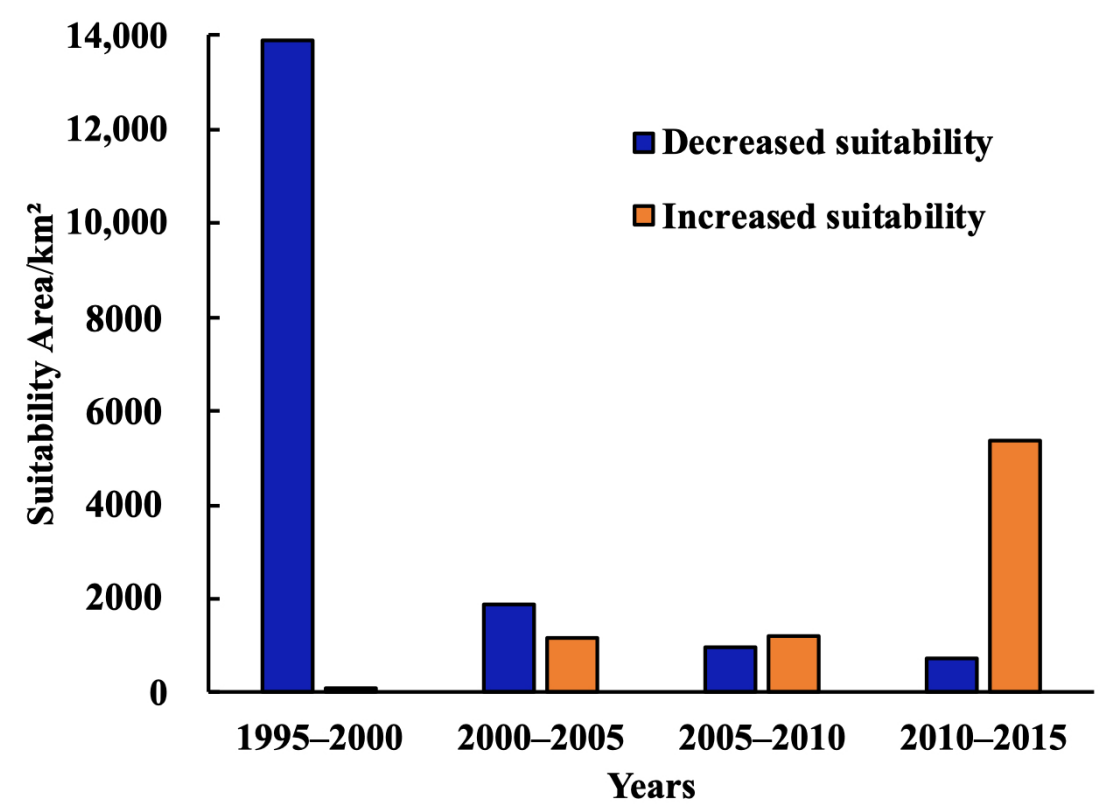

Figure 6. Changes in habitat area suitable for Anatidae in the four intervals between 1995 and 2015 in TGRR. Blue and orange indicate decreased and increased suitability, respectively. 


\section{Discussion}

Our MaxEnt model result showed that the dam impoundment affected Anatidae habitat distribution and area from 1995 to 2015. Anatidae habitats in the TGRR were distributed mainly along the Yangtze River main stream and the surrounding areas before the TGP, and the surrounding areas largely disappeared after the TGP, particularly in Chongqing City and Jiangjin District. The main factors affecting the changing were temperature before the Three Gorges Project (TGP) and elevation after the TGP. From the AUC and TSS values used to evaluate our result, we found that our results are credible and can provide the basis for scientific waterbird conservation and sustainable development of the reservoir.

We simulated the habitat suitable for Anatidae using the MaxEnt model and estimated the model accuracy using AUC and TSS values based on the input species occurrence records and random pseudo-absences data. The AUC and TSS values are currently considered to be the standard method for assessing the accuracy of predictive distribution models. However, each value has its drawbacks and advantages [32,33], so we used both to estimate model accuracy. Sample size affects the accuracy of the MaxEnt model [34]. The simulation results for 1995 were less accurate than those for other periods. This difference was because the distribution data for 1995 were obtained from the literature, and there were fewer data than for the other periods. The MaxEnt model affects not only the sample size effects but also the environmental impact factors, model fit, and prediction [35]. The factors with lower resolution $(1 \times 1 \mathrm{~km})$ that, according to the Anatidae habitat requirements, were sourced from public websites, affected the model's predictive accuracy to a certain degree. However, to increase predictive accuracy, we excluded the factors in spatial autocorrelation in the broad TGRR to avoid overfitting the model, and used the four species with wide niche breadth in a broad study area. However, these could not predict accurate distribution, and most SDMs only apply to their study area and the selected species [35,36]. Some suitable habitats in our predicted were not suitable for Anatidae, e.g., regions with less water can only be a random and unstable habitat, having little significance for the Anatidae population.

Changes in the importance of temperature were affected by impoundment in the TGRR. Wintering waterbirds exploit resources that are ephemeral in time and space and their availability is temperature-dependent $[37,38]$. Waterbird abundance was positively correlated with temperature anomalies [39]; we therefore inferred that the fluctuation in temperature influences waterbird dynamics with regard to abundance and distribution. However, temperature is less important in winter duck distributions than foraging factors such as food accessibility (e.g., water level) [40] With the impoundment of the TGRR, the importance of the DEM increased. The DEM plays a crucial role in the distribution of species in terms of its effect on waterfowl $[25,41]$. Some adjacent areas may be suitable, such as Poyang Lake [42] and Dongting Lake [43], which are also related to the DEM. The mid-lower Yangtze River is a wintering area for Anatidae, and the TGRR is not the most suitable habitat in the area, but it can serve as a refuge for small populations. Dabbling ducks, such as the mallard and the Chinese spot-billed duck in our study, require sufficient areas of open (i.e., unfrozen) water in which to forage; as a result, some of the dabbling ducks select small areas and poor habitat such as the TGRR.

Compared with the lakes in the mid-lower Yangtze River, which are the main wintering grounds for Anatidae in the East Asian-Australasian Flyway, the TGRR in the upper river has fewer species and lower abundances of individual wintering Anatidae $[44,45]$ because the topography of the TGRR is generally mountainous and hilly, and most of the rivers lack shallow areas and food. Before the TGP, the expected effects of the project on the Anatidae were mildly favorable [28]. After the TGP, the number of Anatidae showed a small increase during the cofferdam power generation period, a fluctuating increase during the trial impoundment period, and a significant increase in the stable impoundment period within the main stream and tributaries of the Yangtze River (except for tributaries in 2009 and 2013) $[27,46]$. In our study, these population dynamics correspond to the change in 
area of suitable Anatidae habitat during every impoundment stage. Therefore, we inferred changes in habitat suitability based on the changing population of Anatidae in every stage.

The dynamic area of suitable Anatidae habitat indicates that suitability was greatly affected by the dam cutoff, and the increased area after the cutoff period demonstrated the capacity for self-recovery of habitat quality. In the lakes, the number of Anatidae [46] also corresponded to the suitable habitat area at every stage, but each stage had its own characteristics. Changshou Lake represented almost all low-suitability habitat for Anatidae in our study. The area of suitable habitat sharply dropped in 2000 and continued to decrease until 2005, and increased thereafter. This dynamic trend in habitat suitability within Changshou Lake differed from the overall trend in the TGRR, and suitable habitat did not begin to increase in Changshou Lake after the cutoff period as it did in the TGRR as a whole. Lakes with weak flow are contaminated by industrial waste water and domestic sewage discharge caused by urbanization and industrial development in the upstream river $[47,48]$. Therefore, the self-recovery of lake ecosystems after impoundment lagged behind that of the rivers with stronger flow. In addition, Hanfeng Lake, which was formed by the impoundment of the TGP in the lower reaches of the Pengxi River, was a low-suitability area for Anatidae until the early to stable impoundment periods. Howevre, similar to Changshou Lake, the Anatidae community has been affected by eutrophication in Hanfeng Lake [49] and rapidly decreased after 2012 [27]. In our study, we did not include pollutionrelated environmental factors to predict habitat suitability. There are many indicators for judging water pollution, and water pollution has complex effects on waterbird numbers, species, and distribution [50]. Generally, waterbird population dynamics serve as one indicator of water quality [51,52], but population dynamics are not predictive of water quality because the effects of waterbirds on increasing salt and nutrient levels in wetlands are not well-understood [53].

In summary, after entering the stable impoundment period, the area of suitable habitat for Anatidae in the Yangtze River, its tributaries, and its lakes reduced compared with before the TGP, but the suitability was less affected by the impoundment during this period. In the TGRR, many water bodies prrovide highly suitable habitats for Anatidae, but there are fewer protected areas or wetland parks in the areas with Anatidae or wetland ecosystems that are conservation targets. There are wetland conservation areas in the reservoir area such as Pengxihe River Wetland Municipal Nature Reserve, Zhongxian County Wetland County Nature Reserve, and Chongqing Dachang Lake National Wetland Park. In addition, the protection of Anatidae in the TGRR is mainly implemented by the forestry bureaus of each district (county), but the specificity and intensity of action by these protection agencies for protecting Anatidae are insufficient. Given the long history of fisheries in the Yangtze River waterway within the TGRR, it is challenging to create new protected areas and natural reserves within areas with habitat suitable for Anatidae along the main stream of the Yangtze River. We propose adding Anatidae as conservation targets within these existing conservation agencies and implementing a waterbird monitoring program for wetlands. The Ministry of Agriculture and Rural Affairs of the People's Republic of China implemented a 10 year fishing ban in the Yangtze River basin beginning on 1 January 2021. We think that this ban will benefit the conservation of Anatidae habitat. We can evaluate the impact of the fishing ban on geese and duck habitats in the TGRR to better analyze future conservation measures.

Author Contributions: Formal analysis, G.S., T.M., and K.P.; investigation, G.S., T.M., F.L., and X.L. (Xiaoyun Liu); writing-original draft preparation, X.L. (Xiuming Li); writing-review and editing, X.L. (Xiuming Li), R.C., and F.Q.; supervision, W.X.; funding acquisition, R.C., W.X., and F.Q. All authors have read and agreed to the published version of the manuscript.

Funding: This research was funded by the National Forestry and Grassland Administration (grant number 2130237-20-401) and the State Council Three Gorges Project Construction Committee (grant number 91127-2018).

Institutional Review Board Statement: Not applicable. 
Informed Consent Statement: Not applicable.

Data Availability Statement: The data presented in this study are available on request from the corresponding author.

Acknowledgments: We would like to thank the reviewers, editors, and Robert Wilkes for their comments and suggestions. The environmental data were provided by WorldClim, National Earth Systems Science Data Center, Geospatial Data Cloud, NOAA, Resource and Environment Science and Data Center, and OpenStreetMap.

Conflicts of Interest: The authors declare no conflict of interest.

\section{Appendix A}

Table A1. Environmental data and corresponding Anatidae records and stage of TGP.

\begin{tabular}{|c|c|c|c|c|}
\hline Environmental Factor Year & Stage & Period & Maximum Water Level (m) & Record Year \\
\hline 1995 & Before the TGP & Before 1997 & - & 1981 and 1986 \\
\hline 2000 & Cut-Off Period & December 1997 to May 2003 & - & 1999 to February 2003 \\
\hline 2005 & Cofferdam Power Generation Period & June 2003 to October 2006 & 135 & November 2003 to February 2006 \\
\hline 2010 & Trial Impoundment Period & November 2006 to September 2010 & 172.8 & November 2006 to February 2010 \\
\hline 2015 & Stable Impoundment Period & After October 2010 & 175 & November 2011 to February 2020 \\
\hline
\end{tabular}

Table A2. Information on the environmental factors.

\begin{tabular}{cccc}
\hline Environmental Factor & Description & Year(s) & Source \\
\hline DEM & Digital Elevation Model & 2000 & Resource and Environment Science and Data Center \\
LUCC & Land-Use/Land-Cover Change & $1995,2000,2005,2010,2015$ & National Earth Systems Science Data Center \\
Population & Spatial Distribution of the Population & $1995,2000,2005,2010,2015$ & National Earth Systems Science Data Center \\
Road & Road Density & $1995,2000,2005,2010,2015$ & Chongqing: National Earth Systems Science Data Center; Hubei: Geospatial Data Cloud \\
Temperature & Monthly mean temperature & $1995,2000,2005,2010,2015$ & National Earth Systems Science Data Center \\
Percipitation & Monthly mean precipitation & $1995,2000,2005,2010,2015$ & National Earth Systems Science Data Center \\
\hline
\end{tabular}

\section{References}

1. Carboneras, C. Family Anatidae (ducks, geese and swans). In Handbook of Birds of the World; del Hoyo, J., Elliott, A., Sargatal, J., Eds.; Lynx Edicions: Barcelona, Spain, 1992; Volume 1, pp. 536-629.

2. Amat, J.A.; Green, A.J. Waterbirds as Bioindicators of Environmental Conditions. In Conservation Monitoring in Freshwater Habitats; Hurford, C., Schneider, M., Cowx, I., Eds.; Springer: Dordrecht, The Netherlands, 2010; doi:10.1007/978-1-4020-9278-7-5.

3. Liang, J.; Meng, Q.; Li, X.; Yuan, Y.; Peng, Y.; Li, X.; Li, S.; Zhu, Z.; Yan, M. The influence of hydrological variables, climatic variables and food availability on Anatidae in interconnected river-lake systems, the middle and lower reaches of the Yangtze River floodplain. Sci. Total Environ. 2021, 768, 144534, doi:10.1016/j.scitotenv.2020.144534

4. Bregnballe, T.; Clausen, P.; Fox, A.D. Responses of autumn-staging ducks and Coot Fulica atra to the Skjern River Valley wetland restoration project. Wildfowl 2019, 69, 28-44.

5. Farago, S.; Hangya, K. Effects of water level on waterbird abundance and diversity along the middle section of the Danube River. Hydrobiologia 2012, 697, 15-21, doi:10.1007/s10750-012-1166-1.

6. Silva, T.L.D.; Oliveira, M.D.S.; Rocha, R.J.D.S.; Pitelli, R.A. Water-level controlled reservoir as refugia for waterbirds in an urban landscape. Ornithol. Res. 2020, 28, 151-160, doi:10.1007/S43388-020-00023-0.

7. Zarei, F.; Maleki, L.; Gholamhosseini, A.; Hosseini, S.N.; Pezeshk, J.; Esmaeili, H.R. Man-made waterbodies in Kurdistan province, western Iran, as refugia for waterbirds. Sandgrouse 2019, 41, 1-14.

8. Dimalexis, A.; Pyrovetsi, M. Effect of water level fluctuations on wading bird foraging habitat use at an irrigation reservoir, Lake Kerkini, Greece. Colon. Waterbirds 1997, 244-252, doi:10.2307/1521690.

9. Mwaura, F. The influence of geographic and morphometric factors on the distribution of water bird species in small high altitude tropical man made reservoirs, Central Rift Valley, Kenya. Afr. J. Ecol. 2009, 48, 676-690, doi:10.1111/j.1365-2028.2009.01165.x.

10. Ma, Z.; Cai, Y.; Li, B.; Chen, J. Managing wetland habitats for waterbirds: An international perspective. Wetlands 2010, 30, 15-27, doi:10.1007/s13157-009-0001-6.

11. Hirzel, A.H.; Lay, G.L. Habitat suitability modelling and niche theory. J. Appl. Ecol. 2008, 45, 1372-1381, doi:10.1111/j.13652664.2008.01524.x.

12. Tian, B.; Zhou, Y.; Zhang, L.; Yuan, L. Analyzing the habitat suitability for migratory birds at the Chongming Dongtan Nature Reserve in Shanghai, China. Estuar. Coast. Shelf Sci. 2008, 80, 296-302, doi:10.1016/j.ecss.2008.08.014.

13. Naugle, D.E.; Johnson, R.R.; Estey, M.E.; Higgins, K.F. A landscape approach to conserving wetland bird habitat in the prairie pothole region of Eastern South Dakota. Wetland 2000, 20, 588-604, doi:10.1672/0277-5212(2000)020[0588:ALATCW]2.0.CO;2. 
14. Gallon, R.K.; Robuchon, M.; Leroy, B.; Le Gall, L.; Valero, M.; Feunteun, E. Twenty years of observed and predicted changes in subtidal red seaweed assemblages along a biogeographical transition zone: Inferring potential causes from environmental data. J. Biogeogr. 2014, 41, 2293-2306, doi:10.1111/jbi.12380.

15. Almpanidou, V.; Schofield, G.; Kallimanis, A.S.; Türkozan, O.; Hays, G.C.; Mazaris, A.D. Using climatic suitability thresholds to identify past, present and future population viability. Ecol. Indic. 2016, 71, 551-556, doi:10.1016/j.ecolind.2016.07.038

16. Araújo, M.B.; New, M. Ensemble forecasting of species distributions. Trends Ecol. Evol. 2007, 22, 42-47, doi:10.1016/j.tree.2006.09.010.

17. Leroy, B.; Bellard, C.; Dubos, N.; Colliot, A.; Vasseur, M.; Courtial, C.; Michel B.; Alain C.; Ysnel, F. Forecasted climate and land use changes, and protected areas: The contrasting case of spiders. Divers. Distrib. 2014, 20, 686-697, doi:10.1111/ddi.12191

18. Bellard, C.; Thuiller, W.; Leroy, B.; Genovesi, P.; Bakkenes, M.; Courchamp, F. Will climate change promote future invasions? Glob. Chang. Biol. 2013, 19, 3740-3748, doi:10.1111/gcb.12344.

19. Holopainen, S.; Arzel, C.; Dessborn, L.; Elmberg, J.; Gunnarsson, G.; Nummi, P.; Pöysä, H.; Sjöberg, K. Habitat use in ducks breeding in boreal freshwater wetlands: A review. Eur. J. Wildl. Res. 2015, 61, 339-363, doi:10.1007/s10344-015-0921-9.

20. Yuan, Y.; Liang, J.; Huang, L.; Long, Y.; Sheng, S.; Peng, Y.; Wu, H.; Zeng, G. Effects of environmental factors on the distribution of dominant wintering waterfowl species in East Dongting Lake wetland, South-central China. Chin. J. Appl. Ecol. 2013, 24, 527-534.

21. Liang, J.; Hua, S.; Zeng, G.; Yuan, Y.; Lai, X.; Li, X.; Li, F.; Wu, H.; Huang, L.; Yu, X. Application of weight method based on canonical correspondence analysis for assessment of Anatidae habitat suitability: A case study in East Dongting Lake, Middle China. Ecol. Eng. 2015, 77, 119-126, doi:10.1016/j.ecoleng.2015.01.016.

22. Valerie, S.; Susan, K.S.; Barry, R.N. Vulnerability of Breeding Waterbirds to Climate Change in the Prairie Pothole Region, U.S.A. PLoS ONE 2014, 9, e96747, doi:10.1371/journal.pone.0096747.

23. Kearns B.V. Patterns and Pathways of Lead Contamination in Mottled Ducks (Anas Fulvigula) and Their Habitat. Ph.D. Thesis, Kansas State University, Manhattan, KS, USA, 2015.

24. Yang, D.; Wang, W. Changes and driving forces of Anatidae's potential habitat connectivity in Beijing-Tianjin-Hebei region from 1980 to 2015. Res. Environ. Sci. 2019, 32, 547-556.

25. Azita, F.; Leila, H. Migratory waterfowls as indicators to assess the protection efficiency in Iran. Acta Ecol. Sin. 2018, 38, 429-443, doi:10.1016/j.chnaes.2018.03.003

26. Su, H.; Ma, Q.; Xu, Z.; Zhang, X. Dynamic of the bird distribution status in winter along the Changjiang River of the Three Gorges Reservoir before and after the water level rising to $139 \mathrm{~m}$. Chin. J. Zool. 2005, 40, 92-95.

27. Su, H.; Xiao, W.; Wang, J.; Xu, Z.; Li, W.; Liu, F.; Liu, X.; Zhang, X.; Wang, Y. On alterations of water Level of the Xiaojiang River in winter and of groups of bird spices in the Three Gorges Reservoir Area before and after the water level rising of the reservoir. J. Southwest China Norm. Univ. 2012, 37, 41-48.

28. Zhang, J.; Xiong, T.; Luo, M. Avifauna in the three-gorges reservoir and the prediction of its evolution. In Proceedings of the Collection of Articles for the 60th Anniversary of the Foundation of the Zoological Society of China, Beijing, China, 1994; pp. 90-112.

29. Hu, H.; Xiao, H.; Pan, M.; Dai, X.; Tang, Z. Survey on the water fowl on the Yangtze River above Gezhouba. Chin. J. Ecol. 2000, 19, $12-15$.

30. Phillips, S.J.; Anderson, R.P.; Schapire, R.E. Maximum entropy modeling of species geographic distributions. Ecol. Model. 2006, 190, 231-259, doi:10.1016/j.ecolmodel.2005.03.026.

31. Dai, N.; Shao, M.; Zeng, B.; Shang, X.; Chen, L. Group characteristics of Chinese Merganser (Mergus squamatus) during the wintering period in Poyang Lake watershed, Jiangxi Provin. Acta Ecol. Sin. 2012, 3, 3170-3176.

32. Lobo, J.M.; Jiménez-Valverde, A.; Real, R. AUC: A misleading measure of the performance of predictive distribution models. Glob. Ecol. Biogeogr. 2008, 17, 145-151, doi:10.1111/j.1466-8238.2007.00358.x.

33. Leroy, B.; Delsol, R.; Hugueny, B.; Meynard, C.N.; Barhoumi, C.; Barbet-Massin, M.; Bellard, C. Without quality presence-absence data, discrimination metrics such as TSS can be misleading measures of model performance. J. Biogeogr. 2018, 45, 1994-2002, doi:10.1111/jbi.13402.

34. Hong-You, J.; Hsy-Yu, T.; Ching-An, C.; Yen-Hsueh T. Effects of Sample Size on Accuracy of MaxEnt: A Case Study of Fagus hayatae. Quart. J. For. Res. 2014, 36, 101-114.

35. Adam B.S.; Maria J.S. Testing the ability of species distribution models to infer variable importance. Ecography 2020, 43, 1-13, doi: 10.1111/ecog.05317.

36. Engler, J.O.; Stiels, D.; Schidelko, K.; Strubbe, D.; Quillfeldt, P.; Brambilla, M. Avian SDMs: Current state, challenges, and opportunities. J. Avian Biol. 2017, 48, 1483-1504, doi: 10.1111/jav.01248.

37. Maclean, I.M.D.; Austin, G.E.; Rehfisch, M.M.; Blew, J.; Crowe, O.; Delany, S.; Devos, K.; Deceuninck, B.; Günther, K.; Laursen, K.; et al. Climate change causes rapid changes in the distribution and site abundance of birds in winter. Glob. Chang. Biol. 2008, 14, 2489-2500, doi:10.1111/j.1365-2486.2008.01666.x.

38. Austin, G.E.; Rehfisch, M.M. Shifting nonbreeding distributions of migratory fauna in relation to climatic change. Glob. Chang. Biol. 2005, 11, 31-38, doi:10.1111/j.1529-8817.2003.00876.x.

39. Diego, P.-J.; Web, A.; Hichem, A.; Michal, B.; Taulant, B.; John, J.B.; Luca, B.; Stuart, H.M.B.; Preben, C.; Laimonas, S.; et al. Positive impacts of important bird and biodiversity areas on wintering waterbirds under changing temperatures throughout Europe and North Africa. Biol. Conserv. 2020, 246, 108549, doi:10.1016/j.biocon.2020.108549. 
40. Lars, D.; Fox, A.D.; Petersen, I.K.; Simon, D.; Jens-Christian S. Temperature does not dictate the wintering distributions of European dabbling duck species. Ibis 2012, 155, 80-88, doi:10.1111/j.1474-919X.2012.01257.x.

41. Wen, L.; Saintilan, N.; Reid, J.R.W. Changes in distribution of waterbirds following prolonged drought reflect habitat availability in coastal and inland regions. Acta Ecol. Evol. 2016, 6, 6672-6689, doi:10.1002/ece3.2091.

42. Li, X.; Si, Y.; Ji, L.; Gong, P. Dynamic response of East Asian Greater White-fronted Geese to changes of environment during migration: Use of multi-temporal species distribution model. Ecol. Model. 2017, 360, 70-79, doi:10.1016/j.ecolmodel.2017.06.004

43. Haitao, T.; Diana, S.; Gleb, D.; Sergey, V.; Li, W.; Jialin, L.; Cai, L.; Peter, B.; Lei, G.; Zeng, Q. Combining modern tracking data and historical records improves understanding of the summer habitats of the Eastern Lesser White-fronted Goose Anser erythropus. Authorea 2020, doi:10.22541/au.160525090.02348020/v1

44. Shan, J. The Bird Species Siversity, Population Dynamics of the Endangered Bird Species and Conservation Gap Analysis in the Poyang Lake. Ph.D. Thesis, Northeast Forestry University, Harbin, China, 2013.

45. Chen, J.; Zhou, L. Guild structure of wintering waterbird assemblages in shallow lakes along Yangtze River in Anhui Province, China. Acta Ecol. Sin. 2011, 31, 5323-5331.

46. Su, H.; Xiao, W. Status of wintering birdsalong the Changiiang River of the Three Gorges Reservoir Area before and after different water storage stages. Chin. J. Zool. 2017, 52, 911-936.

47. Gao, J.Z.; Tang, Q.; Long, Y.; Zhang, X.B.; He, X.B. Sources analysis and ecological risk evaluation on heavy metals in Changshouhu Reservoir sediments. Yangtze River 2020, 4, 20-25, doi:10.16232/j.cnki.1001-4179.2020.04.004.

48. Dan, Y.; Shen, Z.W.; Yu, F.Q.; Zhang, C.; Ni, Z.H.; Chen, Y.K.; Li, Y. The analysis of microbial diversity in the sediment of Changshou lake of Chongqing in autumn. J. Chongqing Norm. Univ. Nat. Sci. 2019, 5, 80-85.

49. Yang, J.; Zhang, L.; Wang, J.; Zhai, S.T.Q.Q.; Qiu, Q. Algal community distribution and evaluation in backwater area of the Pengxi river under the designed water storage level of three gorges reservoir. J. Southwest Univ. (Nat. Sci.) 2010, 32, 88-95, doi:10.3724/SP.J.1077.2010.10305.

50. Daniel, L.; Suzanne, H.; Philip, R.; David, B. Future of the Fauna of Western New South Wales; Royal Zoological Society of New South Wales: Mosman, Australia, 1994; pp. 149-154; doi: 10.7882/RZSNSW.1994.00i.

51. Perry, M.C.; Deller, A.S. Review of factors affecting the distribution and abundance of waterfowl in shallow-water habitats of chesapeake bay. Estuaries 1996, 19, 272, doi:10.2307/1352232.

52. Ormerod, S.J.; Tyler, S.J. Birds as indicators of changes in water quality. Birds Monit. Environ. Chang. 1993, 179-216, doi:10.1007/978-94-015-1322-7-5.

53. Anthony, S. Relationships between waterbird ecology and river flows in the Murray-Darling Basin; CSIRO Land and Water: Clayton, Australia, 1997. 